\title{
Risk of primary brain tumour after breast cancer
}

\author{
Anne M Drewes ${ }^{1}$, Maria E Møller ${ }^{2}$, Rasmus Hertzum-Larsen², Gerda Engholm² and Hans H Storm² \\ ${ }^{1}$ University of Aarhus, Aarhus C, Denmark \\ ${ }^{2}$ The Danish Cancer Society, Denmark (Kræftens Bekæmpelse), København Ø, Denmark
}

Correspondence should be addressed to H H Storm: hans@cancer.dk

\begin{abstract}
Introduction: Cancer registry data in the USA indicated that women diagnosed with breast cancer before the age of 40 were at increased risk of a new primary tumour within the brain and women aged 50 years or above were at lower risk than expected. Our aim was to investigate if similar results could be found in Danish population-based data, considering an explanatory role of hormonal status.

Methods: Our study cohort included all women diagnosed with breast cancer below the age of 60 between 1978 and 2013 in Denmark. A total of 47,920 women were followed up in the Danish Cancer Registry for primary brain cancer. Standardized incidence ratios (observed/expected cases (O/E)) were used to estimate the risk of getting a primary brain tumour in the breast cancer cohort.

Results: Data indicated an increased tendency of brain cancer following breast cancer at ages below 60 years $(\mathrm{O} / \mathrm{E}=1.24)$. For premenopausal women (age $<49$ at the diagnosis of breast cancer) the O/E was 1.25. Stratifying by time of breast cancer diagnosis, we observed an increased risk of being diagnosed with a brain tumour among women aged 49 years or younger at breast cancer diagnosis between 2004 and 2013.

Conclusion: The results indicate an increased tendency of developing a primary brain tumour in women with previous breast cancer history. Whereas the finding in premenopausal women is in line with the SEER data, the finding among postmenopausal is not. Primary brain tumours in breast cancer patients call for research in genetics and hormones to establish common risk factors.
\end{abstract}
Key Words
- breast cancer
brain tumour
- oestrogen
- progesterone
- NORDCAN

\section{Introduction}

Survival after breast cancer has improved substantially worldwide over recent decades. Due to the high and increasing incidence of breast cancer in the developed world, the survivor cohort is big, and the possibility of long-term follow-up allows us to study common risk factors and consequences of the treatment. Schoenberg in 1975 (1) and Helseth in 1989 (2) already demonstrated an increased risk of meningioma in breast cancer patients from Connecticut and Norway, respectively. Apart from ionising radiation, we have limited knowledge on risk factors for brain tumours, and for breast cancer hormone-related factors, for example, null parity, late age pregnancies, overweight, alcohol consumption and genetic mutations (BRCA1 and BRCA2), explain less than $1 / 3$ of cases. The trend in incidence for cancer of the breast and brain for the Danish population alone and in the combined Nordic data (Fig. 1) demonstrates a remarkable correlation over time. This called for further study. An analysis from United States Surveillance, Epidemiology, and End Results Program (SEER) on data from 1993-2000 showed that women diagnosed with breast cancer before the age of 40 had an increased risk of a new primary brain tumour $(\mathrm{O} / \mathrm{E}: 1.80$ (Table 1)) (3). On the contrary, a significantly lower risk
This work is licensed under a Creative Commons Attribution-NonCommercial 4.0 International License. ded from Bioscientifica.com at 04/26/2023 06:34:56AM 
Denmark

Incidence: ASR (World), Female age 0-59

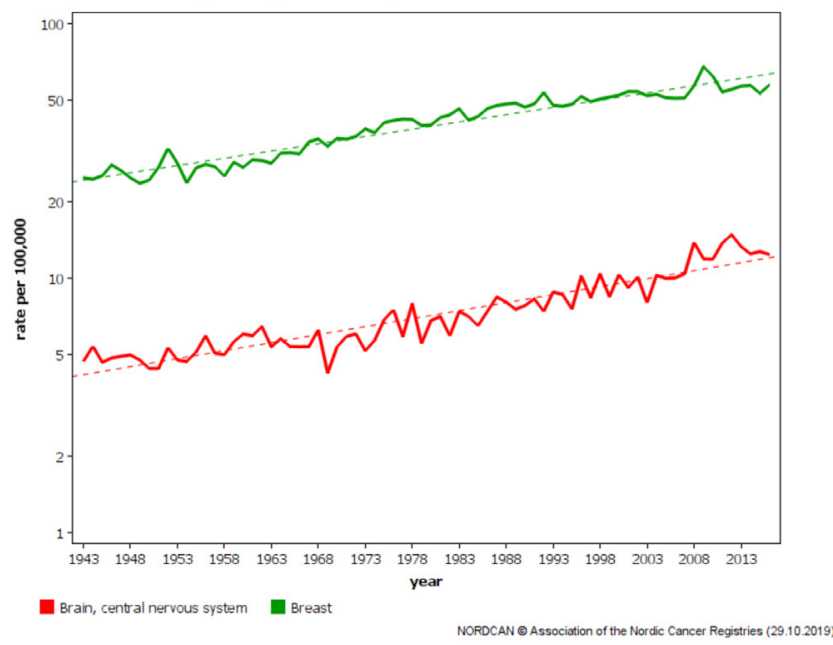

Nordic countries

Incidence: ASR (World), Female age 0-59

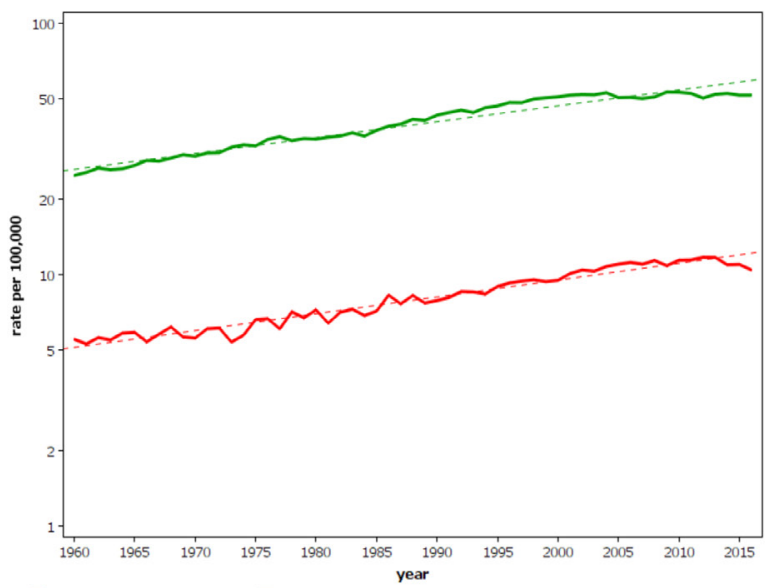

Brain, central nervous system Breast

Figure 1

Age-standardized rates (W) of breast cancer and brain cancer among women in Denmark and in the Nordic countries over time. Data from NORDCAN database (5; http://www.ancr.nu).

was observed in women diagnosed with breast cancer in the ages of 50-59 years (O/E: 0.85) (3).

Menopause on average starts at the age of 51 (4). If there is an increased risk of brain tumour in premenopausal women with breast cancer and a protective effect in postmenopausal women, hormonal levels (oestrogen and progesterone) could possibly have a role in the risk for developing a second primary brain tumour. Therefore, we aimed to investigate whether the findings in the US SEER data could be replicated in Danish population-based data with a view to a possible explanatory role of the hormonal status. Our hypothesis was that premenopausal women had an increased risk and postmenopausal women a decreased

Table 1 Trends for developing primary brain tumour after a primary breast cancer in the USA, 1993-2000. Data from (3).

\begin{tabular}{|c|c|c|c|}
\hline & 0 & $\mathbf{E}$ & O/E \\
\hline \multicolumn{4}{|l|}{ USA } \\
\hline \multicolumn{4}{|l|}{ Age } \\
\hline$<40$ & 15 & 8.33 & $1.80^{\mathrm{a}}$ \\
\hline $40-49$ & 42 & 35.12 & 1.2 \\
\hline $50-59$ & 141 & 166.7 & $0.85^{a}$ \\
\hline
\end{tabular}

a $P<0.05$.

risk of developing a primary brain cancer after a history of breast cancer.

\section{Background}

As seen elsewhere in the developed world, breast cancer is the most common cancer among women in Denmark (ICD10: C50). The incidence was 4.897 new cases per year between 2009 and 2013, and the number has been increasing over the last five decades (Fig. 1) (5). The aetiology of breast cancer is multifactorial and may involve interaction between environmental factors, hormonal levels, genetic factors and lifestyle $(6,7,8)$. A well-known risk factor is the use of hormone replacement therapy, especially the oestrogen-progestagen combination, which increases risk compared to non-users $(9,10)$.

Tumours in the brain and CNS (ICD-10: C70-72, C75.1-3, D32-33, D35.2-4, D42-43, D44.3-5) are rare. In the period between 2009 and 2013, annually 830 women in Denmark were diagnosed with a brain tumour, and overall, this number was slightly higher than that of men (5). The incidence of tumours within the brain and CNS has increased gradually during the last 30 years for both genders, but especially during the last 10-15 years (Fig. 1). The most common type of primary brain tumour among adults is glioblastoma: men have the highest incidence (in contrast to the case in meningioma) and women have the highest rates (11). Glioblastoma originates from the glia cells and is considered as one of the most aggressive of all malignancies in the brain (12). In the USA, the annual incidence of gliomas account for approximately 5 cases per 100,000 a year, with $60-70 \%$ of those being glioblastomas $(13,14)$. Meningiomas are benign tumours and account for about $19 \%$ of tumours within the brain and CNS (15).

\section{Materials and methods}

This study is a retrospective follow-up study based on pseudonyminised data from the Danish Cancer Registry.

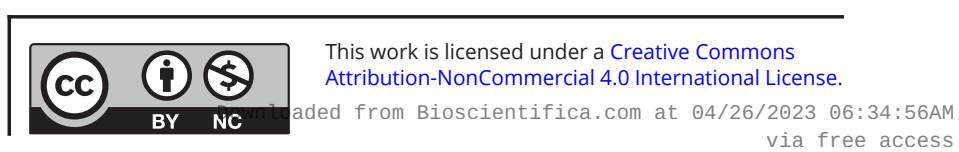


Therefore according to Danish law, neither approval from an ethical committee nor consent from patients was required. In Denmark, all clinicians including pathologist/cytologist are obliged by administrative order (law) to report all newly diagnosed primary tumours to the Danish Cancer Registry. The Danish Cancer Registry has a long history going back to 1943, and it is known to be of high quality and is consequently extensively used for research. In 2004, methods of registration were changed from a semi-manual system to a fully automated data capture and case resolution system, linking already computerised hospital-based information and data from the national pathology register, supplemented with information from the national cause of death register and some paper notifications from primary care (16). We selected 125,802 patients reported with primary breast cancer (ICD10: C50) between 1978 and 2013 from the Danish Cancer Registry and excluded 16,814 with a previous cancer; 703 men, 60,359 women older than 60 years at breast cancer diagnosis (as in the American data), two with unknown status, and two with asynchronous end-date and start-date and two with diagnosis and death occurring at the same day. For analysis, the cohort included 47,920 women diagnosed with a first primary breast cancer. This cohort was followed up in the Danish Cancer Registry for the incidence of cancer in the brain and CNS (ICD10: C70-72+C75.1-3+D32-33+D35.2-4, D42-43+D44.3-5). Each patient was followed from the date of breast cancer diagnosis to which ever occurred first; the first occurrence of a brain cancer diagnosis, death, loss to follow-up or end of study follow-up on the 31st of December, 2013.

Expected numbers were calculated based on the ageand gender-specific population-based incidence rates for brain tumours in Denmark, applying the person-years at risk in the cohort to the relevant time and age-specific rates. The indirect age and period standardized incidence ratios were calculated as observed numbers $(\mathrm{O})$ divided by expected numbers (E) (O/E). We estimated 95\% confidence intervals of the standardized incidence rates assuming a Poisson distribution (17).

\section{Results}

Overall, we observed 241 brain tumours and expected 194.5 brain tumours.

An increased tendency of brain cancer following a diagnosis of breast cancer at ages below 60 years was found $(\mathrm{O} / \mathrm{E}=1.24 ; 95 \% \mathrm{CI}: 1.09 ; 1.41)$. For premenopausal women (i.e. age $<49$ at breast cancer diagnosis) the $\mathrm{O} / \mathrm{E}=1.25$ (95\% CI: 1.03; 1.53) (not found in tables).

Our data and thereby the O/E of a primary tumour brain after breast cancer in the period between 1978 and 2013 in Denmark is presented in Table 2. A tendency of increased brain tumour risk was observed in every age group for women with a previous breast cancer diagnosis between 1978 and 2013.

In the years between 2004 and 2013, a significantly increased risk was observed compared to expected for women diagnosed with a breast cancer at age $40-49$ years, $\mathrm{O} / \mathrm{E}=2.01$ (95\% CI: 1.10; 3.37). Furthermore, from 1993 to 2003 the observed risk for women aged 50-59 was also significantly increased compared to expected, $\mathrm{O} / \mathrm{E}=1.45$ (95\% CI: $1.12 ; 1.84)$. The only group with decreased risk was women younger than 40 years and diagnosed between 1978 and 1992; however, this outcome was not significant $\mathrm{O} / \mathrm{E}=0.62$ (95\% CI: $0.23 ; 1.36)$.

In Table 3 we present the risk of developing a brain tumour by years after breast cancer diagnosis. A significantly increased risk was observed after $5-10$ years compared to expected risk, $\mathrm{O} / \mathrm{E}=1.38$ (95\% CI: 1.06; 1.76).

The morphology distribution of the brain tumours is presented in Table 4 . The most dominant, observed brain tumour types were meningioma and glioma. Meningiomas represented $24 \%$ of all brain tumours between 1978 and 2013 followed by gliomas, which represented $21 \%$.

\section{Discussion}

Our hypothesis was based on observations from the US SEER registries (3). An increased risk of brain cancer was

Table 2 Number of brain tumours (O) and O/E ratio by age and year of breast cancer diagnosis.

\begin{tabular}{|c|c|c|c|}
\hline & Age at diagnosis & $\mathbf{0}$ & O/E $(95 \% \mathrm{Cl})$ \\
\hline \multicolumn{4}{|c|}{ Period with breast cancer } \\
\hline \multirow[t]{3}{*}{ 1978-1992 } & $<40$ & 6 & $0.62(0.23-1.36)$ \\
\hline & $40-49$ & 50 & $1.30(0.96-1.71)$ \\
\hline & $50-59$ & 46 & $1.00(0.74-1.34)$ \\
\hline \multirow[t]{3}{*}{$1993-2003$} & $<40$ & 8 & $2.19(0.94-4.31)$ \\
\hline & $40-49$ & 24 & $1.02(0.65-1.51)$ \\
\hline & $50-59$ & 66 & $1.45(1.12-1.84)$ \\
\hline \multirow[t]{3}{*}{ 2004-2013 } & $<40$ & 3 & $2.10(0.42-6.14)$ \\
\hline & $40-49$ & 14 & $2.01(1.10-3.37)$ \\
\hline & $50-59$ & 24 & $1.23(0.79-1.83)$ \\
\hline \multirow[t]{3}{*}{ Total 1978-2013 } & $<40$ & 17 & $1.16(0.67-1.85)$ \\
\hline & $40-49$ & 88 & $1.27(1.02-1.57)$ \\
\hline & $50-59$ & 136 & $1.23(1.03-1.45)$ \\
\hline
\end{tabular}

Cohort of Danish female breast cancer patients younger than 60 years at diagnosis between 1978 and 2013. 
Table 3 Number of brain tumours $(\mathrm{O})$ and O/E ratio of brain tumours by follow-up time.

\begin{tabular}{|c|c|c|}
\hline Time after breast cancer & 0 & O/E (95\% Cl) \\
\hline 0 to $<1$ year & 15 & $1.23(0.69-2.03)$ \\
\hline 1 to $<5$ years & 55 & $1.21(0.91-1.58)$ \\
\hline 5 to $<10$ years & 64 & $1.38(1.06-1.76)$ \\
\hline 10 years or more & 107 & $1.18(0.97-1.43)$ \\
\hline Total 1978-2013 & 241 & $1.24(1.09-1.41)$ \\
\hline
\end{tabular}

Cohort of Danish female breast cancer patients younger than 60 years at diagnosis between 1978 and 2013.

observed in women with breast cancer below 40 years of age at breast cancer diagnosis, and a decreased risk was observed for women diagnosed with breast cancer after the age 50 years. In the Danish data we overall observed a slightly increased tendency of brain cancer following a diagnosed breast cancer at ages below 60 years. Stratifying by time of breast cancer diagnosis, we observed an increased risk of getting a brain tumour after breast cancer among women at 49 years or younger at breast cancer diagnosis between 2004 and 2013. This correlates with what was seen in the US data. However, we also found an increased risk in the 50+-year breast cancer patients contrary to the decreased risk seen in the United States. This increased risk might be due to general improvement in access to diagnostic tools over time and that diagnostics of brain tumours among elderly is more prioritised today than previously in Denmark. The incidence of brain and breast tumour, in general, increased over time (Fig. 1).

Several causes may influence our ability to compare and interpret the data from the USA and Denmark. Primarily, the number of brain cancer cases was small in Denmark, and so our analysis is therefore subject to random variation. Moreover, a primary brain tumour following a breast cancer is a rare event, but previously it has been noted as clinically relevant with a new primary cancer in the

Table 4 Brain tumour morphology distribution.

\begin{tabular}{lcccc}
\hline Morphology & & Frequency & & Percentage (\%) \\
\cline { 1 - 1 } Glioma & 50 & 58 & 20.8 \\
Meningeoma & 3 & 24.1 \\
Haemangioma & 82 & 1.2 \\
Benign brain tumour & 14 & 34.0 \\
Malignant brain tumour & 3 & 5.8 \\
Neuroepithelial tumour & 16 & 1.2 \\
Neuroma & 14 & 6.6 \\
Adenoma & 1 & & 5.8 \\
Unspecified $^{a}$ & & & 0.4 \\
\hline
\end{tabular}

Cohort of Danish female breast cancer patients younger than 60 years at diagnosis between 1978 and 2013.

aMissing re-encoding. follow-up of breast cancer patients. Nevertheless, one may speculate if registration and differences in cancer reporting influence the results. Errors in reporting may introduce observation bias. Furthermore, since the American data has been published, new and better diagnostic technology has been developed, where more precise methods have been put into use $(18,19)$. Misclassification may occur when, for example, a metastasis from a breast cancer to the brain is registered as a primary brain tumour. We have no information from the US study, whether the brain tumours were histologically proven or whether the diagnoses were based on imaging techniques. A case report by Che-Chao Chang et al. suggests that patients with a breast cancer and concurrent brain tumour(s) have been diagnosed to have a metastatic lesion in the brain, exclusively based on their image findings and without further pathologic verification (20). This may of course vary depending on the country. If the majority of brain tumours were diagnosed as metastatic lesions of breast cancer, this could lead to an overestimation of the risk of metastatic lesions, hence, an underestimation of primary brain tumours. We were unable to study specific brain tumour morphologies. However, those arising from glia and meninges could be interesting to look into due to the brain tumour morphology distribution, which shows that gliomas and meningiomas are the second and third most common brain tumour type in Denmark. This indicates that they are likely to represent a great part of the brain tumours included. Similarly, a stratification of morphology in the primary breast cancer population could have strengthened our ability to identify a possible association between oestrogen receptor-positive breast cancers and brain tumours. A thorough study including the morphology of brain tumours as well as breast cancer is needed to shed light on this possible registration bias.

The aetiology for brain tumours is mostly unknown. Meningiomas are more common among women than men and are reportedly to grow during pregnancy (21), where hormonal levels of oestrogen and progesterone increase. Lately, a link between the use of exogenous hormones and the development of a primary brain tumour has been indicated. The risk of developing a glioma increased by 90\% in women using hormonal contraception for more than 5 years (22). Studies have shown that hormonal replacement in younger women (aged 15-49 years) increases the risk of getting a glioma, and increased risk has been reported with use of combined oestrogen and progestagen, but especially in relation to progestagen use (22). The study included the group of women after menopause (55-84 years old) and found no association

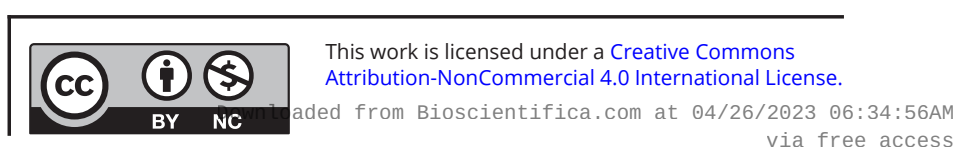


between hormone replacement therapy and development of gliomas; however, further studies were suggested (22).

It is known that the use of exogenous hormones exerts a higher risk of getting breast cancer. Current use of hormone replacement therapy, especially of oestrogen and oestrogen-progestagen combination increases risk compared to non-users $(9,10)$. Furthermore, breast cancer patients, who are sensitive to oestrogen via the oestrogen receptor, benefit from the medical drug tamoxifen. Tamoxifen is a non-steroidal drug that, among others effects, has an anti-oestrogenic effect primarily responsible for the inhibition of breast tumour cells (23).

A study showed that tamoxifen might also have a therapeutic effect on gliomas through its direct action on mitochondrial complex I inhibition in animals. The use of tamoxifen in gliomas emphasizes the theory of the oestrogenic role in the development of gliomas (12). Furthermore, a study found that women with a primary breast cancer, who were not treated with tamoxifen, had an increased risk of developing a meningioma (24). On the contrary, women treated with tamoxifen for their breast cancer had a risk of developing a meningioma close to the risk of the general population (24). The study furthermore suggests that the two types of tumours, breast and meningioma, may share aetiological factors, such as oestrogen (24).

Recent genetic studies have shown a link between the breast cancer susceptibility gene BRCA2, Fanconi anemia and brain tumours (medulloblastoma) constituting a new syndromic association (25). A comprehensive analysis of DNA repair gene variants (26) found a link between BRCA-1 interacting protein 1 (BRIP1) and meningioma. The truncating mutations in BRIP1 is related to lowrisk variants for breast cancer. The association between meningioma and breast cancer is mostly seen in females aged 50-70 years, where exogenous hormones are at play and, interestingly, both tumours express functional progesterone and oestrogen receptors on their cell membranes.

\section{Conclusion}

Overall, we observed an increased tendency in the Danish population of brain tumours after a breast cancer. The results did indicate an increased risk of developing a primary brain tumour in premenopausal women with a previous breast cancer history in the years 2004-2013. This may indicate a hormonal factor in brain cancer as seen in breast cancer corroborated by the more recent genetic studies. However, an increased trend was also observed in postmenopausal women where the hormonal level (oestrogen and progesterone) is lower but where exogenous hormones may play a role. Our findings are not inconsistent with the US data. However, a direct comparison is not possible. This is partly due to a small cohort causing our analysis to be subject to random variation, but also due to development in the field of diagnostics since the US data was collected. However, since the publication of SEER data from 1973 to 2000, the technology for diagnosing brain tumours has improved and offered to elderly patients. Nevertheless, primary brain tumours in breast cancer patients call for research in genetics and hormones to establish common risk factors. More detailed and larger studies are needed to draw further conclusions.

\section{Declaration of interest}

The authors declare that there is no conflict of interest that could be perceived as prejudicing the impartiality of the research reported.

\section{Funding}

This research did not receive any specific grant from any funding agency in the public, commercial or not-for-profit sector.

\section{Author contribution statement}

Anne M Drewes performed drafting, design and critical revision of the manuscript and tables, including few calculations. Maria E Møller performed drafting, design and critical revision of the manuscript. Rasmus HertzumLarsen performed statistics and critical revision of the manuscript. Gerda Engholm performed statistics and critical revision of the manuscript. Hans Storm performed drafting, design and critical revision of the manuscript.

\section{Acknowledgement}

The authors thank the Danish Cancer Registry for the great help with the data.

\section{References}

1 Schoenberg BS, Christine BW \& Whisnant JP. Nervous system neoplasms and primary malignancies of other sites. Neurology 1975 28 817-823. (https://doi.org/10.1212/wnl.25.8.705)

2 Helseth A, Mork SJ \& Glattre E. Meningioma and cancer of other sites: an analysis of the occurrence of multiple primary neoplasms in meningioma patients in Norway from 1955 through 1986. APMIS 198997 738-744. (https://doi.org/10.1111/j.1699-0463.1989. tb00471.x

3 Curtis R, Freedman D, Ron E, Ries L, Hacker D, Edwards B, Tucker M \& Fraumeni JJ. New malignancies among cancer survivors: SEER cancer registries, 1973-2000. In New Malignancies Following Breast Cancer. Bethesda, MD, USA: NCI, 2006. (https://doi.org/10.1136/ jech.2007.063560)

4 Greendale GA, Lee NP \& Arriola ER. The menopause. Lancet 1999 353 571-580. (https://doi.org/10.1016/S0140-6736(98)05352-5) 
5 Engholm G, Ferlay J, Christensen N, Hansen HL, Hertzum-Larsen R, Johannesen TB, Kejs AMT, Khan S, Ólafsdóttir E, Petersen T, et al. NORDCAN: Cancer Incidence, Mortality, Prevalence and Survival in the Nordic Countries, Version 8.1 (28.06.2018). Copenhagen, Denmark: ANCR, 2018. (available at: http://www.ancr.nu/)

6 Danaei G, Vander Hoorn S, Lopez AD, Murray CJL, Ezzati M \& Comparative Risk Assessment collaborating group (Cancers). Causes of cancer in the world: comparative risk assessment of nine behavioural and environmental risk factors. Lancet 2005366 1784-1793. (https://doi.org/10.1016/S0140-6736(05)67725-2)

7 Key TJ, Verkasalo PK \& Banks E. Epidemiology of breast cancer. Lancet Oncology 20012 133-140. (https://doi.org/10.1016/S14702045(00)00254-0)

8 Beral V, Bull D, Doll R \& Peto R. Familial breast cancer: collaborative reanalysis of individual data from 52 epidemiological studies including 58,209 women with breast cancer and 101,986 women without the disease. Lancet 2001358 1389-1399. (https://doi. org/10.1016/S0140-6736(01)06524-2)

9 Beral V. Breast cancer and hormone-replacement therapy in the Million Women Study. Lancet 2003362 419-427. (https://doi. org/10.1016/S0140-6736(03)14065-2)

10 National Collaborating Centre for Cancer (UK). Familial Breast Cancer: Classification and Care of People at Risk of Familial Breast Cancer and Management of Breast Cancer and Related Risks in People with a Family History of Breast Cancer. Cardiff, UK: National Collaborating Centre for Cancer, 2013. (available at: https://www. ncbi.nlm.nih.gov/books/NBK247567/)

11 Preston-Martin S, Reema M \& Reema C. Nervous System in Schottenfeld $D$ and Fraumeni JF Cancer Epidemiology and Prevention, p. 1179. Oxford, UK: Oxford University Press, 2006. (https://doi.org/10.1093/ acprof:oso/9780195149616.001.0001)

12 He W, Liu R, Yang SH \& Yuan F. Chemotherapeutic effect of tamoxifen on temozolomide-resistant gliomas. Anti-Cancer Drugs 201526 293-300. (https://doi.org/10.1097/CAD.0000000000000197)

13 Stupp R \& Roila F. Malignant glioma: ESMO Clinical Recommendations for diagnosis, treatment and follow-up. Annals of Oncology 200920 (Supplement 4) iv126-iv128. (https://doi. org/10.1093/annonc/mdp151)

14 Wen P \& Kesari S. Malignant gliomas in adults. New England Journal of Medicine 2008359 492-507. (https://doi.org/10.1056/ NEJMc086380)

15 Markopoulos C, Sampalis F, Givalos N \& Gogas H. Association of breast cancer with meningioma. European Journal of Surgical
Oncology 199824 332-334. (https://doi.org/10.1016/S07487983(98)80019-X)

16 Gjerstorff ML. The Danish Cancer Registry. Scandinavian Journal of Public Health 201139 (7 Supplement) 42-45. (https://doi. org/10.1177/1403494810393562)

17 Breslow NE \& Day NE. Statistical methods in cancer research. Volume II-the design and analysis of cohort studies. IARC Scientific Publications 198782 1-406.

18 Muir CS, Storm HH \& Polednak A. Brain and other nervous system tumours. Cancer Surveys 1994 19-20 369-392.

19 Tzias D, AM O'Flynn E, Allen SD, Wilson M \& Current AR. Status and new developments in breast cancer diagnosis and detection. European Oncology and Haematology 20139 21. (https://doi.org/10.17925/ EOH.2013.09.1.21)

20 Chang CC, Tien CH, Tai SH, Chuang MT, Sze CI, Hung YC \& Lee EJ. High-grade glioma in a patient with breast cancer. Asian Journal of Surgery 201437 162-166. (https://doi.org/10.1016/j. asjsur.2012.06.007)

21 Hsu DW, Efird JT \& Hedley-Whyte ET. Progesterone and estrogen receptors in meningiomas: prognostic considerations. Journal of Neurosurgery 199786 113-120. (https://doi.org/10.3171/ jns.1997.86.1.0113)

22 Andersen L, Friis S, Hallas J, Ravn P, Kristensen BW \& Gaist D. Hormonal contraceptive use and risk of glioma among younger women a nationwide case-control study. British Journal of Clinical Pharmacology 201579 677-684. (https://doi.org/10.1111/ bcp.12535)

23 Furr BJ \& Jordan VC. The pharmacology and clinical uses of tamoxifen. Pharmacology and Therapeutics 198425 127-205. (https:// doi.org/10.1016/0163-7258(84)90043-3)

$24 \mathrm{Ji}$ J, Sundquist J \& Sundquist K. Association of tamoxifen with meningioma. European Journal of Cancer Prevention 201625 29-33. (https://doi.org/10.1097/CEJ.0000000000000133)

25 Offit K, Levran O, Mullaney B, Mah K, Nafa K, Batish SD, Diotti R, Schneider H, Deffenbaugh A, Scholl T, et al. Shared genetic suceptibility to breast cancer, brain tumors, and fanconi anemia . Journal of the National Cancer Institute 200395 1548-1551. (https:// doi.org/10.1093/jnci/djg072)

26 Bethke L, Murray A, Webb E, Schoemarker M, Muir K, McKunney P, Hepworth S, Dimitropoulou P, Lophatananon A, Feychting M, et al. Comprehensive analysis of DNA repair gene variants and risk of meningioma. Journal of the National Cancer Institute $2008 \mathbf{1 0 0}$ 270-276. (https://doi.org/10.1093/jnci/djn004)

Received in final form 20 November 2019

Accepted 9 December 2019

Accepted Manuscript published online 9 December 2019 https://ec.bioscientifica.com

https://doi.org/10.1530/EC-19-0498 (c) 2020 The authors Published by Bioscientifica Ltd

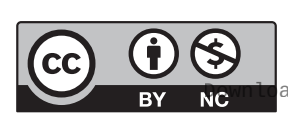

This work is licensed under a Creative Commons Attribution-NonCommercial 4.0 International License. ded from Bioscientifica.com at 04/26/2023 06:34:56AM 